University of Nebraska - Lincoln

DigitalCommons@University of Nebraska - Lincoln

To Improve the Academy

Professional and Organizational Development

Network in Higher Education

1996

\title{
Moving Toward a University Environment Which Rewards Teaching: The Faculty Developer's Role
}

Delivee L. Wright

University of Nebraska-Lincoln, dwright1@unl.edu

Follow this and additional works at: https://digitalcommons.unl.edu/podimproveacad

Part of the Higher Education Administration Commons

Wright, Delivee L., "Moving Toward a University Environment Which Rewards Teaching: The Faculty Developer's Role" (1996). To Improve the Academy. 371.

https://digitalcommons.unl.edu/podimproveacad/371

This Article is brought to you for free and open access by the Professional and Organizational Development Network in Higher Education at DigitalCommons@University of Nebraska - Lincoln. It has been accepted for inclusion in To Improve the Academy by an authorized administrator of DigitalCommons@University of Nebraska - Lincoln. 
Wright, D.L. (1996). Moving toward a university environment which rewards teaching: The faculty developer's role. In L. Richlin (Ed.), To Improve the Academy, Vol. 15 (pp. 185-194). Stillwater, OK: New Forums Press and the Professional and Organizational Development Network in Higher Education. Key words: Faculty Development, Faculty Development Role, Instructional Development, Rewards

\section{Moving Toward a University Environment Which Rewards Teaching: The Faculty Developer's Role}

\section{Delivee L. Wright}

University of Nebraska-Lincoln

This article describes the role of the faculty developer in a departmentally-focused, campus-wide program to revise the rewards system in an AAU-Land Grant University. This process took into account the local values and attitudes of a department as well as the broader mission and values of the institution. It emphasizes a sense of faculty ownership of decisions combined with the collaborative efforts of academic administrators, faculty, and faculty developers.

\section{Background}

In this decade, faculty developers have a pressing need to support their institutions in re-examining the fundamental rewards system which influences the work of faculty. The time is right for change in the direction of a more balanced view of faculty roles and tasks in academia. The literature of higher education calls for improvements in the quality of instruction that our colleges and universities provide 
students. In 1993-94, Diamond reported that a majority of chairpersons, deans, and administrators at research universities recognized a pressing need 'to modify the system to recognize and reward teaching." At the same time, faculty feel the pressure to produce more publications, do more research, get more grants, and contribute more to their professional societies.

In a study of the relationships between rewards and teaching, Fairweather (1993) concluded that "efforts to enhance undergraduate education...have a long way to go to change such a deeply seated reward structure." In the end, to enhance undergraduate education, the faculty and administrative cultures which so strongly support research must learn to see teaching as an important scholarly contribution (Wright \& O’Neil, 1994).

In 1991, a study by the Carnegie Foundation for the Advancement of Teaching concluded that the path for career advancement in research-intensive institutions was affected very little by "what is happening in the classroom." A related finding was that the "student evaluation of courses taught" was among the "most widely used indicators for tenure decisions in all institutions."

Among U. S. faculty developers who rated improvement practices in which they had the greatest confidence in potential for improving the quality of teaching in their universities, identified "recognition of teaching in tenure and promotion decisions as having highest potential, and 'Deans and heads fostering the importance of teaching responsibilities" was second (Wright \& O'Neil, 1994). The issue of teaching rewards is clearly a fundamental concern in supporting the efforts of our field to have a positive impact on academic quality.

As Aitken and Sorcinelli (1994) point out, while the motivation for good teaching is primarily intrinsic, faculty report the need for rewards. Not just salary rewards, but also such intangibles as publicity, noticing efforts to improve teaching, presenting ideas and programs on teaching, etc.

\section{Role for Faculty Developers}

Faculty developers have the potential for playing a fundamental role promoting change in the rewards system. Of course, it is the role 
of academic administrators and faculty to make decisions related to promotion, tenure, and other rewards processes. However, the collaboration of administrative leadership with the knowledge and energy of faculty developers provide a powerful liaison for working toward this common goal of rewarding teaching.

"Deans and academic vice-presidents can cause things to happen-planting ideas, nurturing them, soliciting support from faculty leadership, and pushing ideas through an often tortuous route of dialogue and revision until these ideas are ultimately owned by the organizational culture to produce change" (Green, 1990). They can create an environment which values and supports teaching through "symbolic leadership" to assist in reshaping of the institutional culture so that teaching becomes a vital valued activity (Green, 1990).

Faculty developers, on the other hand, bring the skills of process facilitation and program development to the problem so that the likelihood of acceptance by the academic community can be enhanced. They also bring an understanding of effective teaching, learning styles, and the literature on the evaluation of teaching. They use the literature on change and on decision-making processes to enhance the quality of impact generated.

The purpose of this paper is to describe how faculty developers' (FDs) efforts contributed to a campus-wide change process which was oriented to the revision of the rewards system in support of teaching See Figure 1. This example is from the University of Nebraska-Lincoln, an AAU, Land Grant, and Research I university which considers teaching an important part of its mission.

\section{Roles in Project Initiation}

\section{Needs Clarification}

Initially, the FD worked with a group of faculty to propose a small grant from the local Teaching Council to establish a discussion group on the issues of the improvement, evaluation, and reward of teaching. The FD met with this group and supported it with pertinent readings and information. She facilitated discussions from which came a focused need to address the question of rewarding teaching in a research 
university. She invited participation of a college dean who was especially interested in supporting teaching to join in the discussion of practical ways to address the issue. The group collaborated with the campus-wide Teaching and Learning Center (TLC) to organize workshops to bring in external resource people who would bring more awareness to the campus on the evaluation and reward issues. The FD led workshops and discussions on defining what constitutes effective teaching and on how effective teaching might be measured. Seeking out appropriate literature and facilitating faculty study of it were important FD functions. One of the fundamental tasks was to break down the barriers to communication across unit (department and college) lines.

\section{Proposal Development}

As a clear sense of purpose and need developed among faculty groups, they were encouraged to consider the idea of developing a proposal for a larger grant to work on the problem of rewarding teaching in a research university. The FD was not only principal proposal writer, but also identified strong leadership. She worked with the faculty discussion group and the interested dean to help identify faculty to serve as directors of the proposed team project, and to engage a second dean who administered the largest college on campus.

Although this proposal was not funded, the Fund for the Improvement of Postsecondary Education (FIPSE) awarded the team a small planning grant. This was enough encouragement to generate more action. As part of the planning grant, a survey was conducted to determine faculty attitudes about the reward of teaching. This data collection brought concrete, local information into the formerly subjective discussions. The FD assisted the faculty leaders in survey design, distribution and analysis. This grant enabled the TLC to hire a graduate student to conduct the survey and write a report on its outcomes. Again, the FD provided the "energy" for following a good idea through with directed action.

\section{Communication of Needs}

Armed with these data on local faculty beliefs, academic admin- 
istrators were invited to examine the results and to work with the faculty. Upper level leaders were alarmed at the views expressed in the data. The FD supported the faculty leaders with pertinent literature, facilitated planning, and committed support for implementing the proposed project. One skeptical dean conducted an additional survey which corroborated the data, and therefore strengthening the case. The FDs support of this project provided the catalytic action to make it happen. While change had to come from faculty and administrators, the FD was the catalyst for that change.

\section{Proposal Resubmission}

With the encouragement and support of the FD, a second and a third proposal were submitted to FIPSE by the faculty leaders with documented administrative support. The Chancellor committed to support the project regardless of external funding, because it was so important to the quality of instruction on the campus. This effort received a positive response, and was funded for a three-year project. Throughout the proposal writing process, the FD served as a planning team member to encourage and propose action as well as to write basic elements of the proposal.

\section{Roles in Project Implementation}

\section{Organizational Support}

Once the grant was awarded, the project development team included: the two faculty directors representing two large colleges (Arts and Sciences and Agriculture), the FDs, and a project assistant. The FD helped to identify departments for participation, faculty members for leadership roles, and processes for encouraging the acceptance of the project in departments. In addition the project was housed in the TLC which was neutral territory for participating units, and could provide operational resources such as office space and equipment, telephones, and accounting and scoring assistance.

\section{Change Guide}

During the implementation phase, the FDs role evolved away 
from innovative idea initiation and stimulation toward one of making the plan happen. The application of change theory was fundamental in translating an idealistic dream into actions that would change the reality of institutional rewards structures. Recognition that some of the campus would be positive about the goals of the project, was tempered with the understanding that others had been well rewarded with the existing system and would not appreciate any attempts to change it.

The importance of having both faculty and administrative teams working in their own ways toward the goal of rewarding teaching and thereby demonstrate a sense of ownership of the change, was recognized. It was also important to have a mechanism for formally communicating ideas between the two groups.

With recognition that both administrators and faculty must be committed to the change, the project established two leadership teams: the Administrative Leadership Team, and the Departmental Leadership Teams. Each assisted in generating decisions on how the project should proceed, and each provided a sense of ownership. The Administrative Leadership Team included Chancellor, Academic ViceChancellor, Deans of participating colleges, Chairs of participating departments, Project Directors, and the FD.

Departmental Leadership teams composed of the Department Chair, the Chair of the Promotion and Tenure (or equivalent) Committee, and a Faculty Project Leader from each participating department met regularly with the Project Directors and the FD. Each department received $\$ 1000$ from the project to support its process and to develop a departmental plan. The faculty Project Leader received $\$ 1000$ in development funds which were to be used in support of teaching.

\section{Resource Provider}

FD resources were needed by each participating department as they worked through a year-long series of tasks with the goals of examining what they were currently doing, examining the appropriate literature, and developing a plan for the future actions in evaluating and rewarding teaching. Connecting literature and people resources 
with the needs at critical times were important functions. Ideas on how they could best use financial resources to move toward development of departmental plans were also needed.

Supportive reference materials were compiled, with permissions of authors, in a notebook. The most succinct and current materials on a wide range of topics were selected to help operationalize effective evaluation and reward of teaching. The materials ranged from thought pieces to pragmatic examples of instruments. These materials were provided from the FDs resource library.

Initially, a workshop was organized to introduce the project to all faculty and to answer questions. This provided the opportunity to diffuse objections or anxieties. An opinionnaire was administered to all faculty to document attitudes within the department, and the resulting data were reported to the department. Each semester two workshops were held for all Departmental Leadership Teams to discuss issues and methods for evaluating teaching, to strategize specific responses to problems, and to report progress

\section{Communications Facilitator}

Each semester, project leaders and the FD met with the Administrative Leadership Team to consult on a variety of concerns. As barriers to rewarding teaching were identified by departmental teams, these were brought to administrators seeking creative solutions or removal of the barriers. These meetings provided a flow of ideas and information which were incorporated immediately into the project. They enhanced the recognition that both faculty and administrators were working toward the same goals and were seeking the exchange of ideas to promote the outcomes sought.

Communication among departments about how each was approaching the problem of developing their plan was encouraged among departmental leadership teams and among individuals. It was necessary to be aware of what each department had to offer others in terms of interesting ideas, approaches and materials.

In the first year, four departments were identified that had shown interest in examining the evaluation and reward of teaching. Each had already made some initial efforts on their own and were viewed as 
units with high probability of success. The second year, the plan was for four new departments; however, eight requested participation. By the third year, an additional 16 departments from these two colleges had worked through the process and developed plans.

Throughout this process, the faculty regularly requested special workshops and discussions on related topics. The FD regularly consulted on processes for use within various departments, and generally served as a point-of-contact.

In addition to the sharing of project information at professional meetings and in articles, formal reports and information sessions for perspective departments were needed. Materials were designed for disseminating information about this project including: brochures, annual reports, a final report, a process manual, a book of plans, and a bibliography of supportive materials.

\section{Post-Project Sustaining Activity}

When the grant is completed, all too often the project also disappears. In this case, the pervasive engagement of the faculty developers and the TLC resulted in the continuation of the project with minimal costs. Support from the Senior VCAA encouraged an additional twenty departments in four other colleges to work through the same process to develop their own plans for the recognition and reward of teaching. The process and the materials had been developed with grant funds, so a much greater benefit could be accrued with a little more development support.

A "cascade effect" has occurred with each project spinning naturally into another level of implementation. An additional three-year grant for dissemination of this process to other campuses was funded by FIPSE, and subsequently, an additional dissemination project for Land-Grant Colleges was funded by the U. S. Department of Agriculture and the Kellogg Foundation. Four conferences and one teleconference have been held to assist participating campuses in implementation of this project. Additional funded projects with the National AAHE Peer Review Project and a local FIPSE grant for a Peer Review Project has also resulted from having people who are informed, interested and able to respond to these special tasks. 
Considerable recognition has come to the Faculty Project Directors who have received both local and national acclaim for the work they have fostered. Publications, presentations, and scholarly contributions resulting from the project as well as merit pay, promotion, and awards have enhanced their own careers and reputations.

The greatest benefit has been the evolving climate which is supportive of quality teaching. The ease of acceptance and encouragement of work with teaching portfolios, with peer review, and with the formation of a Distinguished Teaching Academy was undoubtedly made possible by the faculty dialogues and the values clarified during the departmental processes of examining how good teachers are identified and rewarded.

\section{Conclusion}

This project has been the happy combination of a great many people who worked systematically toward a common campus goal while keeping the human-scale needs of individual faculty in their own departments in focus. It has been a collaborative process among academic administrators and faculty leaders combined with the energy from the "engine" of the faculty developers to generate the broadest possible impact on enhancing the value of teaching. Most importantly, it has underlined the importance of doing the best work possible when teaching our students.

In faculty development terms, it combines principles of organizational development and change as well as principles of instructional and professional development of faculty. When all these elements are orchestrated together, the benefits can be significant.

\section{References}

Aitken, N.D. \& Sorcinelli, M.D. (1994). Academic leaders and faculty developers: creating an institutional culture that values teaching. To Improve the Academy, 13, 63-77.

Diamond, R. (1993-94). Changing priorities in higher education: Promotion and tenure. Teaching Excellence, [bulletin], 5, 3.

Fairweather, J.S. (1993). Teaching, research, and faculty rewards: A summary of the research findings of the faculty profile project. University Park, PA: National Center on Postsecondary Teaching, Learning and Assessment.

Green, M.F. (1990). Why good teaching needs active leadership. In P. Seldin and Associ- 
ates (Eds.), How administrators can improve teaching: Moving from talk to action in higher education (pp. 45-62). San Francisco: Jossey-Bass.

The Carnegie Foundation for the Advancement of Teaching. (1991). Research-intensive vs. teaching- intensive institutions. Change, 23, 23-26.

Wright, W. A. \& O'Neil, C. (1994). Teaching improvement practices. To Improve the Academy, 13, 5-37.

\author{
Contact: \\ Delivee L. Wright \\ Director of the Teaching \& Leaming Center \\ University of Nebraska - Lincoln \\ 121 Benton Hall \\ Lincoln, NE 68588-0623 USA \\ (402) 472-3079 \\ (402) 472-4932 FAX \\ dwright@unlinfo.unl.edu
}

Delivee L. Wright has been the Director of the Teaching and Learning Center at the University of Nebraska - Lincoln since 1979. She has served as facilitator for a FIPSE Project on the "Reward of Teaching" on her campus. A faculty developer for 28 years, she has been active in the POD Network in Higher Education since 1977, serving on the CORE Committee for six years, and was Executive Director (President) from 1989-1991. 